\title{
'TÚ NO TIENES DONDE IR (Y YO SÍ)'. DE CÓMO EL MIEDO AL CONTAGIO IMPACTA EN LAS TRABAJADORAS MIGRANTES EMPLEADAS EN EL HOGAR
}

\section{'YOU HAVE NOWHERE TO GO (AND I DO)'. HOW FEAR OF CONTAGION AFFECTS MIGRANT DOMESTIC WORKERS}

Sílvia Bofill-Poch* y CARMen Gregorio GIL **

Resumen: En el contexto actual de la COVID-19 nos interrogamos sobre los efectos que el miedo al contagio tiene en las condiciones laborales de las mujeres de origen inmigrante empleadas de hogar y cuidados en España. Partiendo de la posición de liminaridad en que las condiciones de reproducción del empleo de hogar y su marco regulatorio sitúan a las trabajadoras, analizamos tres dimensiones: la recomposición de las relaciones de poder y autoridad entre empleada, persona cuidada y familiares que implican las nuevas formas de convivencia en los hogares; la sobrecarga emocional que supone para las trabajadoras el contexto de confinamiento domiciliario, distancia y aislamiento social; y el modo en que las fronteras de género, clase y raza entre un "nosotros/as" y un "otras" se reactivan en el marco de las relaciones serviles que caracterizan al sector. El miedo como categoría social surge de un marco regulatorio laboral y migratorio que priva a estas trabajadoras de sus derechos, y de una economía del cuidado que descuida y invisibiliza los abusos y sufrimientos que caracterizan el sector.

* Universitat de Barcelona. bofill@ub.edu

** Universidad de Granada. carmengg@ugr.es 
Palabras clave: empleo de hogar; mujeres migrantes; covid-19; miedo; liminaridad.

Abstract: In the current COVID-19 context, we analyze how fear of contagion impacts on the working conditions of female migrant domestic workers in Spain. The article opens up the liminality in which the conditions of domestic work reproduction, and its regulatory framework, place these workers. It focuses on three related dimensions. First, how the power relations between workers, the person who is cared for and the family are reworked, and the new forms of coexistence within the households that it entails. Second, the emotional overload that home lockdown and social isolation means for these female workers. Third, how the gender, class and race boundaries between "us" and "others" are reshaped within the framework of domestic work servile relationships. Fear as a social category stems from a labour and immigration regulatory framework that deprives these female workers of their rights, and from a care economy that neglects and makes invisible the abuses and suffering that characterize this sector.

Key words: Domestic Work; Female migrants; COVID-19; Fear; Liminality.

La emergencia sociosanitaria que estamos viviendo en España consecuencia de la pandemia derivada de la enfermedad por coronavirus (COVID-19) ocasionada por el virus SARS-CoV-2 está poniendo de manifiesto la fragilidad de nuestro modelo de organización social de los cuidados y atención a la dependencia, teniendo un fuerte impacto en las personas que cuidan, bien sea a sus familiares como parte de sus obligaciones de parentesco, a otras personas como parte de su compromiso social u otro tipo de lazos o bien sea a aquéllas que lo hacen de forma remunerada. Con esta situación de emergencia y excepcionalidad se ha hecho más que patente y de forma dramática aquello en lo que venimos insistiendo durante décadas desde una perspectiva de género, sea desde el análisis económico (Carrasco, 2003), sociológico (Duran, 2012) y/o antropológico (Comas d'Argemir, 1995; Del Valle, 2003), y que venimos denunciando de muchas maneras: que el peso de los cuidados se soporta sobre la base de su no reconocimiento económico e invisibilidad, y por eso: "cuidar cuesta y ha de ser tenido en cuenta en los presupuestos" (Duran, 2002); que hay que poner los cuidados en el 
centro de la economía, de la reproducción social al objeto de atender nuestra condición vulnerable como seres humanos (Carrasco, 1991; Comas d'Argemir, 1995, 2000). Igualmente venimos llamando la atención sobre la existencia de una "crisis global de cuidados" o de "sostenibilidad de la vida" producida por el modelo económico neoliberal (Carrasco, 1991, 2003; Gregorio Gil, 1998; Pérez-Orozco, 2006; Herrero, 2019).

La noción de cuidado, junto a otras que se han ido proponiendo desde la teoría feminista como trabajo doméstico, trabajo reproductivo, empleo de hogar, ha ido cobrando fuerza dentro del movimiento feminista, mostrando su potencia a nivel mundial en la Huelga Internacional Feminista que tuvo lugar el 8 de marzo de 2018, a la que se adhirieron más de 170 países $^{1}$ y que volvió a convocarse en años sucesivos, incorporando entre unos de sus ejes de reivindicación los cuidados. La noción de cuidados ha pasado a ser una categoría teórica y política en la que el movimiento feminista se reconoce a nivel planetario al objeto de sacar de la invisibilidad histórica las actividades imprescindibles para que la vida funcione en el día a día (Esteban, 2019; Aruzza, Bhattacharya y Fraser, 2019) porque "sin nosotras no se mueve el mundo". Espacio político en el que las mujeres inmigrantes, en tanto trabajadoras en este sector, alzan su voz al objeto de denunciar las relaciones de explotación y racialización en las que se reproduce este empleo, que viene a unirse a las desigualdades que supone el no reconocimiento de derechos plenos de ciudadanía, por su condición de inmigrante (Maquieira, Gregorio y Gutiérrez, 2000; Gregorio Gil, 2004; Mestre, 2005; Monteros, 2017; Bofill-Poch, 2017; Márquez y Bofill-Poch, 2020). Hemos escuchado durante la pandemia sus propias propuestas apropiándose del discurso político del gobierno de la nación: "Para no dejar a nadie atrás!"2, politi-

1 "Distintos países, un mismo grito contra la desigualdad. Desde Turquía o Pakistán a Brasil y México, organizaciones feministas han convocado movilizaciones en más de 170 Estados para reivindicar los derechos de la mujer" https:// elpais.com/internacional/2018/03/07/actualidad/1520452960_137452.html

2 "Una veintena de asociaciones de mujeres migradas firman el documento de incidencia política, un diagnóstico de cómo ha impactado en ellas la pandemia. No solo denuncian su situación, también realizan una serie de propuestas dirigidas al Gobierno, reivindicando su derecho a un trabajo digno, a una vida libre de violencias y a poder ejercer como ciudadanas y ser escuchadas en las 
zando la noción de cuidados "cuidar y no ser cuidadas"3 o apelando a su discriminatoria condición jurídica \#RegularizaciónYa ${ }^{4}$.

Poniendo nuestro foco de atención en las trabajadoras de hogar y cuidados de origen inmigrante, nos hemos preguntado ¿Qué está significando estar empleada como cuidadora en tiempos de pandemia en los hogares cuando las medidas de seguridad e higiene han de extremarse? ¿Qué nuevos significados de clase, género, raza y diferencia cultural aparecen en este contexto en el que cualquier agente "externo" al hogar puede ser percibido como agente trasmisor del virus, "agente contaminante"? ¿Qué tensiones se han producido entre el requerimiento imprescindible de mano de obra para el cuidado de personas mayores en los hogares y la gestión de los riesgos que ello podría implicar en tanto potenciales portadoras de la enfermedad? ¿Hasta dónde el miedo a la pérdida de nuestros mayores ha conllevado una vulneración aun mayor de los derechos de las trabajadoras de hogar?

\section{APUNTES TEÓRICO-METODOLÓGICOS}

En nuestro análisis partimos de la posición liminar (Álvarez, 2007) en la que las condiciones de reproducción del empleo de hogar sitúan a las trabajadoras, en términos de la posibilidad de negociar sus condiciones laborales y frente a un eventual reclamo de derechos (Bofill-Poch y Márquez, 2021). Un estar entre, “¿muchacha, chacha, alguien más de la familia?” (Gregorio, Alcázar y Huete, 2003) que, en esta ocasión, observaremos en relación con el miedo al contagio y la percepción de vulnerabilidad que acompaña a la pandemia, junto con las medidas adoptadas en relación con nuestro derecho a la movilidad y la distancia social. La condición liminar no podemos observarla al margen de un modelo particular de aten-

estancias políticas" https:/www.elsaltodiario.com/migracion/mujeres-migradasreclaman-vida-libre-violencias-era-post-covid

3 https://www.elsaltodiario.com/opinion/trabajadoras-hogar-cuidados-cuidar-no-ser-cuidadas

4 "El Gobierno debe regularizar masivamente y sin condiciones por justicia social” https://www.elsaltodiario.com/migracion/edith-espinola-gobierno-deberegularizar-masivamente-sin-condiciones-justicia-social 
ción a la dependencia que ha traído como consecuencia la creciente mercantilización del trabajo de cuidados dentro de los hogares de manera imbricada con las políticas migratorias (Gregorio Gil, 2009, 2017), junto a débiles políticas sociales y percepciones culturales bien arraigadas que siguen naturalizando el trabajo de cuidados como un asunto de "mujeres" (Comas d'Argemir, 1995, 2000, 2014; Gregorio Gil, 1998).

La liminaridad que rodea a las relaciones de producción que se dan dentro de los hogares se expresa en cuestiones como la dificultad de diferenciar entre lo que es trabajo de lo que no lo es en el marco de las relaciones de afecto y confianza propias del hogar, junto a ello, la desconsideración del trabajo relacional y afectivo frente al trabajo físico que comportan las tareas de cuidado de personas. A lo anterior se une la indefinición de la autoridad en tanto profesional de los cuidados que tiene que negociar con una autoridad ("no profesional”) prescrita por el parentesco sobre la persona cuidada, pero que además es quién tiene la decisión sobre el mantenimiento o no de la relación laboral ${ }^{5}$. Todo ello hace que la agencia de las trabajadoras se traduzca en un sin fin de estrategias de resistencia cotidianas frente al limitado marco de derechos que recoge el "Régimen de empleadas de hogar" de la que no es sino una relación laboral entre empleada y patronal.

Ante las desigualdades de género, pero también de extranjería y clase social que la pandemia estaba produciendo, no podíamos eludir nuestra responsabilidad como científicas sociales y desde un compromiso público y feminista se gestó el proyecto CUMADE "El cuidado importa. Impacto de género en las cuidadoras/es de mayores y dependientes en tiempos de la COVID-19"6. El proyecto

5 En trabajos anteriores hemos analizado como esta misma posición liminar — asociada a, y/o articulada con, prejuicios arraigados sobre las trabajadoras de origen migrante- impregna los procesos y sentencias judiciales motivados por conflictos en el ámbito laboral, contribuyendo a su indefensión frente a un posible reclamo de derechos y negando su acceso efectivo a la justicia (véase Bofill-Poch y Márquez, 2020; Márquez y Bofill-Poch, 2020; Bofill-Poch y Márquez, 2021).

6 El proyecto está dirigido por Dolors Comas d'Argemir de la Universitat Rovira i Virgili y en él participan otras nueve universidades españolas: Universitat de Barcelona, Universidad de Granada, Universidad de Zaragoza, Euskal Herriko Unibertsitatea, Universidad Complutense de Madrid, Universidad de Murcia, Universidad de Castilla-La Mancha, Universidade da Coruña y Universitat de 
se ha orientado al estudio del impacto de la pandemia sobre las condiciones laborales y socioeconómicas de las personas cuidadoras, remuneradas y no remuneradas, en su articulación con el resto de agentes que hacen parte del modelo de organización social del cuidado en nuestro país, en especial las políticas públicas de atención a la dependencia. Desde un enfoque cualitativo centrado en entrevistas en profundidad, nos hemos acercado a los discursos de las y los diferentes agentes que consideramos relevantes en la organización social del cuidado (social care). Por un lado, hemos entrevistado a las trabajadoras: cuidadoras familiares, trabajadoras de residencias, trabajadoras del servicio de atención domiciliaria, empleadas de hogar y cuidados, y asistentes personales. Por otro, a gerentes y directoras/es de servicios públicos y privados, y responsables políticos. Además, hemos accedido a diferentes organizaciones de la sociedad civil de carácter local, autonómico y estatal, relacionadas con la defensa de los derechos de las trabajadoras de este sector ${ }^{7}$.

Para la redacción de este artículo nos centramos fundamentalmente en el trabajo realizado en el marco de la unidad de trabajo sobre empleadas de hogar y cuidado, donde se hicieron un total de 80 entrevistas, distribuidas territorialmente en Andalucía, Aragón, Castilla-La Mancha, Cataluña, Galicia, Madrid, País Vasco y Valencia $^{8}$. Más en particular, nos basamos en las entrevistas realizadas en Cataluña y Andalucía, un total de 22, repartidas entre trabajadoras (15) — todas ellas de origen latinoamericano, en situación administrativa no siempre regularizada, contratadas en régimen

València. Está financiado por el FONDO SUPERA COVID-19 Santander-CSICCRUE (junio 2020-diciembre 2021).

7 Los territorios en los que hemos trabajado han sido: Andalucía, Aragón, Castilla La Mancha, Cataluña, Galicia Madrid, Murcia, País Vasco y Comunidad Valenciana. En total se han realizado 343 entrevistas, entre los meses de julio 2020 y febrero 2021, la mayor parte de ellas, aunque no todas, conducidas de manera telemática y siempre bajo consentimiento informado. Las entrevistas han sido anonimizadas cuando así nos lo han solicitado, a fin de preservar la identidad personal de nuestras/os participantes.

8 En esta unidad de trabajo participaron 14 investigadoras/es: Cristina $\mathrm{Ba}-$ rrial, Yolanda Bodoque, Sílvia Bofill-Poch, Alessandro Gentile, Carmen Gregorio, Ana Lucía Hernández, Angelina Kussy, Diana Mata-Codesal, Raquel MartínezBuján, Jesús Martínez, Paloma Moré, María Offenhenden, María Pilar Tudela y Laia Ventura. Las reflexiones que aquí exponemos son parte de un trabajo colectivo. 
interno y externo, con y sin contratación formal-y agentes institucionales y de la sociedad civil: asociaciones de trabajadoras, sindicatos, entidades de intermediación laboral y personal sanitario $(7)^{9}$.

Las reflexiones que plantemos aquí parten de la escucha atenta a empleadas de hogar de origen inmigrante entrevistadas para esta investigación, al objeto de analizar los efectos de la pandemia sobre sus vidas, particularmente las dimensiones relacionadas con el desempeño de su trabajo remunerado en el sector del cuidado. Traemos sus voces para responder a nuestros interrogantes, que al tiempo se han ido conformando a partir de esa escucha y en diálogo con los diferentes colectivos sociales con los que hemos tenido ocasión de conversar.

Tras situar la construcción social del miedo (Douglas, 1996) en el marco que regula las condiciones laborales de las trabajadoras en la economía del cuidado, nos adentraremos, en primer lugar, en el análisis del hogar como espacio conflictivo y en relación con ello, en los significados que toma el trabajo de cuidado en el contexto de las normas decretadas para frenar la pandemia, para finalizar mostrando cómo el miedo se inscribe en esos cuerpos "otros" de las trabajadoras de hogar.

\section{LA CONSTRUCCIÓN DEL MIEDO EN EL MARCO REGULATORIO DE LA ECONOMÍA DEL CUIDADO: TRABAJADORAS ESENCIALES, PERO SIN DERECHOS}

Si hay algo que ha venido de la mano de la gestión de la pandemia ha sido el miedo al contagio, como miedo "real" a enfermar y a morir, pero también como dispositivo de control de la población en el sentido foucaultiano. Desde que se decretó el estado de pandemia por parte de la OMS, no hemos dejado de asistir a cifras diarias de muertes, olas y curvas de ascensos de contagios, imágenes de UCIs

9 Los agentes entrevistados han sido: Confederación Sindical de Comisiones Obreras (CCOO), Sindillar/Sindihogar, Mujeres Pa'lante, Mujeres Migrantes Diversas, Mujeres Unidas entre Tierras, Red de Mujeres Latinoamericanas y del Caribe, Coordinadora socio-laboral Anem per feina y Asociación Nosotras Granada, además de personal sanitario de centros de atención primaria y representantes de asociaciones de cuidadores y cuidadoras familiares. 
colapsadas, las insoportables muertes en las residencias de personas mayores (Del Pino et al., 2020), la saturación de los hospitales y centros de atención a la salud y con ello la desatención de nuestros otros padecimientos. Junto a ello el agotamiento de los y las profesionales de la salud, sector en el que también ha habido un significativo número de muertes y nuestro propio agotamiento por lo que está significando la distancia social con nuestros seres queridos. Aunque se pueda argumentar que todo ser humano no está a salvo de contraer el virus, enfermar y morir, la gestión de una pandemia nos muestra que las condiciones estructurales nos sitúan en condiciones de partida muy diferentes para enfrentarnos a ella. Sin duda la de quiénes están en la primera fila combatiendo el virus, los profesionales de la salud y de la atención socio-sanitaria, por usar las metáforas de guerra con las que los medios de comunicación y nuestros propios dirigentes políticos han ido creando la narrativa de la covid (Moré, 2020). También quiénes no han podido mantener sus empleos teletrabajando al hacer parte de los sectores denominados "esenciales" y, por tanto, han tenido que mantener la relación con las personas, clientas y usuarias de bienes y servicios.

Pero más allá del riesgo al que nos expone nuestra actividad laboral, las medidas decretadas para frenar la pandemia, han mostrado de forma descarnada la falta de garantías para amplias capas de la población del ejercicio de los derechos económicos y sociales que promulga nuestro supuesto estado de bienestar social, entre éstas el sector del "empleo de hogar".

En determinados países de la vieja Europa y con débiles sistemas de bienestar social de carácter familiarista, como sería el del Estado español, venimos asistiendo desde la década de los 90 a la emergencia del sector del "empleo de hogar", ocupado en un importante porcentaje por mujeres procedentes del llamado Sur Global (Gregorio Gil, 1998; Herranz, 1999; Benería, 2008; Martínez-Buján, 2011). Según la Encuesta de Población Activa (EPA, 2019), hay en España 580.500 empleadas de hogar de las cuales casi la mitad tienen nacionalidad extranjera [una cifra ligeramente inferior a las 637.000 que había en 2018 según datos de la EPA]. Aunque se estima que son muchas más, dadas las condiciones de irregularidad en las que desempeñan su trabajo en este sector. Se trata de un sector altamente feminizado (el 95\% son mujeres), con un nivel de protección inferior al resto de sectores económicos, especialmente desregulado (el 30\% trabajan en condiciones de 
irregularidad) y sometido a unas condiciones laborales y salariales claramente discriminatorias (Offenhenden, 2017, Díaz-Gorfinkiel y Martínez-Buján, 2018).

La raíz histórica y política por la que el sector económico de "hogar y cuidados"10 ha pasado a ser el sector reservado para las mujeres procedentes del llamado Sur Global la encontramos en el régimen de fronteras instaurado desde el Tratado de Schengen. Europa envejece requiriendo mano de obra joven sin los derechos plenos de ciudadanía como modus operandi (Gregorio Gil, 2017, 2021) para sostener los sectores en crisis de sus economías, en particular una economía invisible cuyo marco de relaciones socioeconómicas acontece en el espacio del hogar, construido como el espacio "privado", libre de la intervención estatal. ¿Cómo explicar que ante el confinamiento domiciliario decretado por el Gobierno de la nación y las medidas dictadas para proteger a los y las trabajadoras que se quedaban sin empleo, se olvidasen de las trabajadoras de hogar y de cuidados? ${ }^{11}$ Trabajadoras que no solo podrían ser despedidas, sino que además, en su caso, se añadían los agravantes que permite el Régimen especial de empleadas de hogar ${ }^{12}$. A saber, el llamado desistimiento o, lo que es lo mismo, la extinción de la relación laboral únicamente por voluntad expresa del contratante; la imposibilidad de cotizar por la prestación de desempleo; la no inclusión en la Ley

10 Formalmente no existe un sector laboral que se denomine como tal, pero englobaría aquellos trabajos que se realizan dentro del hogar regulados por el Régimen especial de "Empleados del hogar", pero también los de "auxiliares de ayuda a domicilio" regulados por los diferentes convenios establecidos en las Comunidades Autónomas en el marco de la Ley de Dependencia 39/2006.

11 Sorprendentemente, el Real Decreto-ley 8/2020, de 17 de marzo, de medidas urgentes extraordinarias para hacer frente al impacto económico y social del COVID-19 — donde se regulan los nuevos procedimientos de suspensión de contratos de trabajo, prestaciones por desempleo, cese de actividad de autónomos/ as, etc.- no menciona esta relación laboral de carácter especial.

12 "Régimen Especial de Empleados de Hogar" de 1424/1985, al que se incorporarán diferentes reformas, en concreto la Ley 27/2011, el Real Decreto 1620/2011 y el Real Decreto-Ley 29/2012. Dichas reformas tienen lugar después de que la Organización Internacional de Trabajo (OIT) aprobase el Convenio 189 sobre las trabajadoras y los trabajadores domésticos al objeto de "promover el trabajo decente para todos mediante el logro de las metas establecidas en la Declaración de la OIT relativa a los principios y derechos fundamentales en el trabajo y en la Declaración de la OIT sobre la justicia social para una globalización equitativa", Convenio que sin embargo aún no ha sido suscrito por el estado español. 
de la prevención de riesgos laborales y, para terminar, el no reconocimiento del derecho a la negociación colectiva.

¿Cómo era posible que en un momento como el que estábamos viviendo frente a una pandemia, que nos confrontaba con nuestra vulnerabilidad e interdependencia, una vez más el gobierno se hubiese olvidado de quiénes se emplean en los hogares, mayoritariamente mujeres e inmigrantes realizando trabajos de hogar y cuidados imprescindibles en la vida diaria? Y aún más si cabe, en una situación de confinamiento domiciliario. Y no solo se hubiese olvidado del reconocimiento de sus derechos largamente reivindicados como trabajadoras y que habría de contemplar en una situación de excepcionalidad, sino también de la urgencia por garantizar su protección como ciudadanas ante una pandemia que requería la provisión de equipos de protección individual para proteger sus vidas y para evitar la propagación del contagio.

El gobierno español reaccionó a la petición elevada por parte de los colectivos de trabajadoras al Presidente del Gobierno, al Vicepresidente de Asuntos Sociales, a la Ministra de Trabajo y Economía Social, al Ministro de Inclusión, Seguridad Social y Migraciones y a la Ministra de Igualdad, expresada en estos términos: "Las trabajadoras de hogar y cuidados nos dirigimos a ustedes, conscientes de la excepcionalidad de los momentos que vivimos y de la responsabilidad que todas las personas debemos ejercer para cuidar el bienestar del conjunto, y precisamente por ello nos vemos obligadas a demandar una vez más la protección de derechos para nuestro colectivo, que se ha visto excluido de las medidas urgentes extraordinarias para hacer frente al impacto económico y social del COVID-19, aprobadas el 17 de marzo. [...] Las trabajadoras de hogar y cuidados, junto al resto de los colectivos de este ámbito, también merecemos ser cuidadas, no es momento para exclusiones u olvidos"13.

La reacción del gobierno fue relativamente rápida. Esta petición le debió sacar los colores a un gobierno que se erigía en defensor de los sectores más vulnerables de la economía y se reconocía promotor de la igualdad de género. El 1 de abril se aprobó el RD 11/2020 de 31 de marzo, el cual abre la posibilidad a cobrar un subsidio extraordinario para empleadas de hogar que estuvieran dadas de alta a la Seguridad Social y hubieran perdido su contrato laboral o reducido

13 Transcripción de la carta de adhesión que fue circulada por diferentes redes sociales. 
su jornada como consecuencia de la pandemia ${ }^{14}$. Lo cierto es que el subsidio no solo llega tarde, sino que deja fuera una parte substancial de las trabajadoras - aquellas cuya situación administrativa no estaba regularizada o que carecían de contrato laboral formal-, además de crear falsas expectativas y mucha frustración entre las trabajadoras (Otxoa, 2020). Las trabajadoras reclaman derechos, no ayudas, y sienten que una vez más, y pese a haber sido reconocidas como esenciales, no se está atendiendo a la especificidad y extrema vulnerabilidad del sector.

\section{EL HOGAR ESCENARIO DE SEGURIDAD ¿PARA QUIÉNES?}

En línea con el discurso público y mediático sobre la prioridad de minimizar la transmisión del virus, las familias hemos interiorizado el miedo al contagio respondiendo mediante diferentes estrategias de vigilancia y control sobre nuestros mayores dependientes. Éstas han ido desde la reagrupación de la persona mayor en el hogar de sus hijos e hijas, a la restricción de algunas de las actividades que antes de la pandemia realizaban fuera del hogar haciendo uso de los servicios públicos, como centros de día, parques u otros lugares de sociabilidad y recreo. La alta mortalidad de personas mayores producida por la propagación del virus en las residencias hace que estos espacios residenciales se perciban como espacios "no seguros". Se instaura en el sentido común la idea de qué en el hogar, con nuestra parentela, estaremos más protegidos del virus por lo que personas mayores que vivían solas o en residencias pasan a vivir en el hogar de sus hijos e hijas. Acoger a una persona necesitada de cuidados en el seno del hogar familiar ha implicado recurrir a mano de obra externa o mantener la ya existente implicando cambios no negociados, como ha sido el cambio del destino del puesto de trabajo a consecuencia del cambio de domicilio de la persona cuidada. Esta situación implica además el desarrollo del trabajo en un nuevo contexto relacional más complejo, no solo por las medidas de seguridad

14 Real Decreto-ley 11/2020, de 31 de marzo, por el que se adoptan medidas urgentes complementarias en el ámbito social y económico para hacer frente al COVID-19 [BOE-A-2020-4208]. 
e higiene adoptadas frente al virus, sino por la gestión de las relaciones sociales en un nuevo espacio convivencial. Como es bien sabido, los hogares tienen sus propias lógicas de funcionamiento marcadas por derechos y deberes que prescribe la edad, el género y el parentesco, estando atravesados por relaciones de poder y autoridad, en contra de la idea del hogar como un lugar en donde las relaciones son armónicas e igualitarias.

Desde esa posición liminar como trabajadora ¿cómo negociar unas condiciones de seguridad e higiene en el trabajo exigibles en una situación de pandemia, cuando lo que se impone es el criterio de quién vive en el hogar, quedando excluida de la toma de decisiones? ¿Qué hacer en una situación de prevención ante el posible contagio cuando uno de los miembros de la familia por ejemplo fuma dentro de la casa, no abre las ventanas y se niega a comprar mascarillas o gel hidroalcohólico? ¿Cómo gestionar las relaciones de convivencia atendiendo a los derechos de la trabajadora en el espacio "privado" del hogar? ¿Cómo gestionarlas ante la desprotección más absoluta — como se muestra en algunos de los relatos que traemos a continuación-cuando se tiene que convivir con el hijo, la hija o el yerno de la persona a la que se cuida?

En el siguiente relato, Eloísa, quien cuida en régimen interno a una mujer de 83 años, cuenta que antes de la pandemia ella “... tenía una situación ideal, porque era una señora muy culta, muy afectuosa, nos entendíamos", pero la decisión tomada por los hijos y la hija de la señora de llevársela a casa de esta última cambió el escenario, y la relación con el yerno de la persona a la que cuidaba se tornó insostenible, abandonando finalmente el "empleo".

Pero ya cuando entramos a ser parte de otro núcleo familiar... el yerno era muy agresivo, sentía que la pobre señora estaba invadiendo su hogar, la hacía sentir muy mal. Lo que he aprendido es que no tendría que inmiscuirme en los asuntos de familia, pero no con esto quiero decir que no me dolía mucho el trato. Una sola vez se me ocurrió decirle a la hija que su esposo le tuviera un poco más de paciencia a la señora... que los adultos mayores eran muy sensibles y más ella que se la había sacado de su entorno y estaba más vulnerable. Y ella pues le dijo a su marido y ahí empezó mi calvario. Ese señor me ha tratado como ha querido. Horrible, me ofendía a diario. Yo me sentí discriminada por mi condición de migrante, aunque tengo mis papeles en regla. Me sentí como una intrusa. Logró que mi autoestima se derrumbara, 
me hacía sentir que yo no era nada, que era peor que una basura, que yo no tenía derecho a nada, que él me podía picar en pedazos, matarme si quisiera, y que por mi nadie iba a sacar la cara. Aguanté por necesidad. En pandemia, si yo no recibo esto, ¿de qué voy a vivir? [...] Te cuento que yo soy una mujer fuerte, yo trato de abstraerme, separar mi trabajo, pero esto me rompió tanto emocionalmente que tuve que decidir entre si yo era la que iba a tener que subsistir, o me iba a enterrar con la propia señora. No pude más, preferí ir a Cruz Roja y que me ayudaran.

Pero además del ambiente conflictivo que describe al trasladarse a otro domicilio para desempeñar su trabajo, le cambiaron sus condiciones laborales, bajándole el salario de $1200 €$ a $600 €$, lo cual nos habla de los abusos cometidos ante la situación de incertidumbre y desregulación del sector.

Me hicieron unas cuentas allá de lo que era la comida y el alojamiento. Te trabajan psicológicamente, te intimidan: 'Mire, ahora no hay nada. Con la pandemia, ¿quién la va a contratar ?'. Yo cuidaba a la señora, pero además tenía que hacer las labores de la casa, cuidarle la niña, me incrementaron cosas que no estaban en lo que hablamos inicialmente. Me llegaron a proponer que cuidara los hijos de la vecina si quería cobrar los $1000 €$. Me pareció un abuso total.

Al compartir la tarea del cuidado con otros miembros de la familia convivientes, el trabajo como cuidadora parece minusvalorarse y depreciarse, perdiendo un espacio de autoridad y reconocimiento tanto afectivo como económico. En estas situaciones, la gestión cotidiana de las medidas de prevención de la covid se dificultan. Es el caso del hogar en el que trabaja Elena, de lunes a sábado en horario de 14 a 20 horas, contratada con un salario de $600 €$ para cuidar a un hombre de 91 años que convive con su hijo. Como ella misma nos relata:

El señor es un pan de Dios, pero el hijo no sale. Tiene el síndrome de la cabaña. Cuando llego me cierra la puerta, me hecha llave, y a veces quiero salir y no está la llave. Yo le digo: 'debe dejar la llave en la puerta', y responde que no, que le da miedo. Fuma mucho. Las persianas las abre, pero las ventanas no las abre para nada y nos ahogamos de calor, no tienes ni idea. Porque él mete el aire acondicionado por minutos y por otros dice que se gasta mucho. Es muy agobiante. De pronto le da la loquera y 
llama al 010, al 016, a todos los 0, vienen los bomberos, viene la ambulancia, vienen todos, quiere que se lleven a su padre y grita: 'quiero que se lo lleven tres días, quiero dormir tranquilo...' Entonces vienen y me preguntan: ‘usted es la cuidadora? ¿qué afecciones ha tenido?'... pero yo no puedo decir nada porque él me está mirando. Me da miedo. Por eso yo prefiero que esté el viejito ahí, siempre estoy con el móvil en la cintura, en el pantalón.

Según lo expuesto, no parece sencillo mantener las medidas de prevención frente a la covid cuando te quitan cualquier tipo de autoridad sobre la gestión de determinadas medidas de higiene en el hogar, aún más cuando la vigilancia se ejerce solo sobre la trabajadora, eximiéndose de la misma a la persona receptora de los cuidados. Otra de nuestras entrevistadas, Luana, se contagió después que el hombre de 75 años que cuidaba regresara a casa tras un ingreso hospitalario y tuviera que ser reingresado a los pocos días por presentar síntomas covid. Por su parte Luana empezó a tener síntomas poco después. La familia la culpó de haber sido vector de contagio. Ella, sin embargo, hace otra lectura.

El hombre era terco y nunca quería ponerse la mascarilla. Yo siempre le decía: 'señor, póngasela, porque usted viene de la iglesia y me va a contagiar a mí y, entonces, yo ¿cómo lo hago? ¿cómo trabajo?'. A regañadientes le tuve que decir a la hermana que, por favor, le llamase la atención porque él no quería, no quería. Decía: 'No, a mí no, ¡que me va a dar! Eso son los que salen mucho'.

El uso responsable de la mascarilla en los hogares se ha convertido en una afrenta difícil para las trabajadoras de hogar, por un lado, porque les espetan directamente que "no son nadie para prohibirles salir a la calle sin mascarilla", pero también porque sienten que no tienen la legitimidad para decir a las familias que deben usar mascarilla.

\section{LOS SIGNIFICADOS DEL CUIDADO: LA INVISIBILIDAD DE LA SOBRECARGA DEL TRABAJO EMOCIONAL}

La pandemia de la covid ha modificado las prácticas y los significados del cuidado en los hogares en sentidos distintos. El miedo al contagio produce cambios visibles en el modo de cuidar: distancia física, uso de equipos de protección, nuevos hábitos de higiene, 
control sobre la movilidad y una actitud permanente de alerta frente a posibles focos de infección. Afecta directamente la dimensión relacional y afectiva del cuidado, por cuanto inhibe no solo físicamente, sino también emocionalmente. La pandemia ha incrementado la sensación de riesgo de aquellas personas que socialmente se perciben como más vulnerables, especialmente personas adultas (ancianas) en situación de mayor dependencia, comportando situaciones de gran aislamiento físico y social en los domicilios, durante y después del estado de alarma. Cuidar en casa se presenta, a ojos de las familias, como la opción más 'segura', pero el miedo ha entrado también en los hogares. Las personas que cuidan a sus mayores de la familia temen ser agentes transmisores del virus, sienten la responsabilidad de protegerles y por ello los confinan y se auto-confinan. Llama la atención que el miedo persiste incluso en casos donde el confinamiento es casi total, y donde las incursiones al exterior son realmente mínimas. El miedo lleva a adoptar medidas que acaban generando más miedo. Ello produce no solo tristeza y depresión, sino también ansiedad e irritabilidad. En este sentido se expresa Marta, presidenta de una asociación de cuidadores familiares.

Antes podías salir, relacionarte, ir a dar un paseo con tranquilidad. Todo esto se ha convertido en miedo. Miedo a contagiarte tú o que se contagie el familiar, porque es un virus que no tienes ni idea donde lo vas a coger. Estás todo el día encerrado con tu familiar en casa. Se crea un círculo vicioso, de que no me toquen lo que tengo, que por mal que esté me funciona. Por mal que estés, prefieres no mover nada: 'es que si lo saco me enganchará el covid'... Coger una mano, dar un abrazo, hacer una caricia... todo esto se ha acabado. La persona cuidada entra en un estado depresivo y en un estado de ansiedad muy grande y tú también. Quizás necesitarías que alguien cuidara de ti. Yo creo que nos están aislando de todo. Todo es cuanto más aislante mejor. Todo el día nos están hablando de muertos...

El cierre de centros y servicios especializados, así como la restricción de todos los espacios de sociabilidad, ha alterado unas rutinas que resultaban esenciales para la estabilidad emocional de las personas mayores con mayor dependencia. Ello ha ocasionado un acelerado deterioro físico y cognitivo, situación que han tenido que afrontar las cuidadoras. Protegerse frente al virus, aislarse de todo peligro exterior, reducir al máximo la interacción social, ha comportado otros riesgos con efectos directos en muchos casos sobre la 
salud física y mental, tanto de las personas cuidadas, como de las personas cuidadoras.

En los casos en los que se ha producido el confinamiento de la trabajadora o, lo que es lo mismo, ha pasado a un régimen de internamiento, sus desplazamientos fuera del hogar se han visto muy reducidos, apenas para realizar las compras o algunas gestiones. Además sus días libres y horas de descanso, a consecuencia de los confinamientos decretados, las pasarán dentro del hogar en el que están empleadas, también, en el caso de las que están en una situación irregular para evadir los controles policiales. En algunos casos ni siquiera salen a comprar alimentos, y es la familia quien lleva la comida a la puerta o realizan las compras en-línea. Se impone a la trabajadora un confinamiento total con la persona cuidada, especialmente durante el estado de alarma y en un contexto donde, si no se convive con ellos, apenas realizan visitas los familiares. Ello produce situaciones de mucho estrés físico y psicológico, donde el espacio vital parece hacerse pequeño, "disminuirse", y donde la persona cuida$\mathrm{da}$, a veces con afectaciones cognitivas severas, no siempre entiende las razones del confinamiento domiciliario y los motivos por los que ningún familiar viene a verla. Así se expresaba Patricia en relación a la persona a la que cuida, una mujer de 92 años con demencia.

Por ratos se le va la mente. Esconde las cosas y luego se enfada porque no las encuentra. Yo le cantaba para que estuviera tranquila, bailaba con ella, pintaba Se agobiaba: 'tengo que ir al centro [de día]'. Se levantaba. La hija la llamaba cada día y le explicaba. En el momento lo entendía y luego se le olvidaba. Y me preguntaba: ‘¿cuándo voy a salir? ¿cuándo voy a ver ? Yo no veo a nadie, estoy sola...', y lloraba. Yo también he sentido agobio.

De esta situación se hace eco Fanny, representante sindical de cCOO.

Las personas mayores tampoco están bien porque ellas también padecen el encierro. Si antes salían a la calle a pasear, a tomar el aire, lo siguen necesitando, pero ahora no lo pueden hacer. Las familias son tan estrictas que les prohíben sacarlos a la calle y les dicen que no toquen nada. Cuando van al médico, van con el miedo de que no pueden tocar nada. Tu imagínate estar con una persona con Alzheimer, Parkinson o demencia senil y pedirle que no toque nada. Lo que hacen son encierros definitivos, a veces, en pisos super pequeños. Hay gente que lleva cuatro y cinco meses sin salir. Es 
un sufrimiento horroroso para ambas partes, porque están sometidos a presión en sus propias casas, como si fuera una prisión. Te vas a levantar al día siguiente y todo va a ser igual, y no sabes cuánto va a durar. Llega un punto en que enferman, pero de depresión, de frustración, de todas aquellas enfermedades que no podemos ver.

$\mathrm{Al}$ sentimiento de abandono, se suman los efectos del encierro y el tedio de una cotidianidad que trastoca todos los hábitos adquiridos. En ocasiones ello conlleva comportamientos agresivos, que pueden acabar en situaciones de maltrato hacia la trabajadora, como la descrita en el caso de Eloísa, interna, trasladada a convivir con la familia de la mujer mayor que cuidaba.

Un encierro sí, un enclaustramiento total. También le echo la culpa a eso. Como fue una situación en la que estabas en un espacio disminuido... una señora que no la quería tener él [el yerno]... Todo esto generaba... como que sacaba lo peor de las personas. Entonces la intolerancia yo lo atribuyo todo esto a la situación del covid, al miedo, a la pandemia, a la inseguridad.

\section{5. 'HE ACEPTADO TODO': EL MIEDO COMO GENERADOR DE OTREDAD Y SERVIDUMBRE}

En nuestro análisis nos hemos querido preguntar hasta qué punto el miedo al contagio y la percepción de vulnerabilidad ha supuesto una activación de las fronteras de género, clase y raza entre un "nosotros/as" y un "otras" en el marco de las relaciones de servidumbre que se producen en el empleo de hogar (Gregorio Gil, 2007, 2009). Una consecuencia directa del miedo al contagio ha sido el despido de las empleadas de hogar ${ }^{15}$. Los colectivos de mujeres migrantes y los sindicatos entrevistados constatan el número elevado de trabajadoras que, desde que se decreta el estado de alarma, han

15 El sector del hogar ha estado fuertemente golpeado por la crisis. El número de personas afiliadas al Sistema especial de empleadas de hogar dentro del Régimen General se vio reducido, pasando de 391.456 altas en enero de 2020 a 372.654 en junio de 2020 (Parella, 2020, p. 106). Aún después de meses de pandemia (según datos de afiliaciones en alta relativos al mes de septiembre comparados con el mes de febrero), las afiliaciones al Sistema especial de empleadas de hogar muestran una caída del 5\%, muy superior al 2,3\% general (Mahía, 2020, p. 77). 
sido despedidas, mayormente de forma verbal, sin preaviso y sin ofrecer ningún tipo de indemnización. Los cambios que la pandemia produce en las situaciones laborales y económicas de las familias empleadoras - teletrabajo, expedientes de regulación temporal, pérdida de empleo- explica en parte los despidos, en la medida que dichos cambios posibilitan —o en ocasiones no dejan más opción que- hacerse cargo directo del cuidado del familiar dependiente. Pero el despido se argumenta también como estrategia para minimizar el riesgo al contagio. Tal y como comenta Fanny, representante sindical de $\mathrm{CCOO}$, "a las familias les da pavor que esa persona [la trabajadora] salga a la calle, se contagie y lleve el covid a la casa".

Cuando no han sido despedidas, las trabajadoras en régimen externo han sufrido cambios significativos en sus condiciones laborales (jornadas laborales y salarios). Los periodos de confinamiento y desescalada, el cierre y reapertura de centros de día, los cambios en las jornadas laborales de las personas empleadoras, han obligado a las trabajadoras a adaptarse a las necesidades cambiantes de éstas, en un contexto en el que la pandemia exacerba otro tipo de miedo quizás más potente para la clase trabajadora y precarizada: el miedo a no encontrar otro empleo. En este contexto de incertidumbre las trabajadoras aceptan cambios de horario y salario sin ser negociados, y sus empleos, temporalmente suspendidos, quedan "en el aire". Por parte de quiénes emplean esperan que la trabajadora permanezca disponible y atenta a eventuales requerimientos.

Otra estrategia a la que las familias han recurrido, justificada por la minimización del riesgo al contagio, ha sido el confinamiento de la trabajadora en el domicilio junto a la persona cuidada. Algunas trabajadoras ya trabajaban en régimen interno, pero las que lo hacían en régimen externo han pasado al régimen interno ante la amenaza de perder su empleo. Pero además en algunos casos, el incremento de la jornada que supone este régimen no ha venido aparejado de un aumento de sueldo: "Cuando me confiné — explica Patricia-me pagó bien, hasta que me dijo que ya no podía pagarme más, que no pensó que eso duraría tanto y que no le alcanzaba el dinero. Su hija me dijo: 'mi mamá no tiene nada"'.

En otros casos, no solo no ha habido aumento salarial, sino que se les ha disminuido el sueldo, en concepto de gastos por alojamiento y manutención, y esgrimiendo el que se les posibilite "un lugar seguro, sin contaminación”, como nos explicaba Isabel, del colectivo Mujeres Unidas entre Tierras. El confinamiento provocado por la 
pandemia, con las implicaciones en la bajada del nivel adquisitivo de las familias, se convierte en retórica justificativa de suspensión de derechos laborales, algo similar a lo que identificaron Briones et al. (2014) durante la crisis económica-financiera del 2008 en relación a este sector laboral.

Con este telón de fondo de desempleo y reducción de ingresos, llegando a niveles altos de pobreza y falta de ocupación (Mahía, 2020), los relatos de las trabajadoras recogidos nos hablan de esa liminaridad entre relaciones laborales y de servidumbre, que no hace sino situarlas en posiciones de total indefensión y vulnerabilidad (Anderson, 2000; Gorban, 2012). Por lo pronto, el miedo al contagio se convierte para estas mujeres sobre todo en el miedo a la pérdida del trabajo y, con ello, de sus ingresos, lo que las coloca en una situación de mayor indefensión en lo que se refiere a la negociación de sus condiciones laborales, más aún en situaciones administrativas de irregularidad como es el caso de Fernanda, que trabaja en régimen de internamiento cuidando a una mujer de 93 años.

La señora tiene su carácter, es muy seca. No le gusta que yo me siente, le gusta que me la pase haciendo los quehaceres todo el rato. Si yo le quiero contestar algo me dice que yo no puedo contestar nada. Que yo no puedo decir nada, que ella es la dueña de la casa y que, si estoy en su casa, se hacen las cosas como ella dice. Si digo alguna cosa, me dice que me van a echar: 'te quedarás sin trabajo y ¿después qué harás? No tienes para donde ir'. Cuando la pandemia, me decía: 'Si tú te enfermas, yo tengo a donde ir a un hospital, pero tú, ¿a dónde vas a ir? Tú no tendrías donde ir porque no tienes nada'. Es la manera de ponerme un cierre en la boca. Ellos hablan con autoridad, te hacen sentir pequeña. [...] Ellos controlan todo el tiempo, por el temor de que me contagie y le pase a su madre. Pero uno lo nota, a ellos no les preocupa que yo me contagie. A ellos les interesa que su familiar esté bien. Lo que yo, como ser humano, pueda vivir o pueda sentir, eso es problema mío.

En una situación como la que se ha vivido ese "no tienes donde ir" expresa el ejercicio del poder apelando al miedo que provoca en la trabajadora la posibilidad de enfermar y no poder ser atendida por la red de salud pública ante situaciones de irregularidad y pobreza. Esta misma expresión de angustia y miedo frente a lo que puede suponer la enfermedad para el mantenimiento del empleo, la encontramos en relatos como el de Luana, quien, como ya mencionamos, se contagió de covid en el lugar de trabajo. 
Me sentía fatal, primero por vivir todo el encierro, segundo por los síntomas. Y pensando mucho, siempre con miedo. Tenía fiebre y estaba sola, me asustaba. Luego, se me pintó el cuerpo de rojo con unas manchas. ‘¿Y qué va a pasar después? ¿Cómo voy a trabajar? ¿Me van a aceptar en el trabajo?’. Eso me causaba ataques de ansiedad. Me vinieron unos dolores en la parte de la cara. Él ahora está internado y yo me quedé sin trabajo. No es tanto la enfermedad, sino el qué pasará después. Tengo que pagar mi habitación, mi comida, mandar a mi hijo a Perú.

Como nos han relatado profesionales del ámbito sanitario, el miedo a perder el empleo les puede llevar a retrasar la decisión de acudir al centro de salud en caso de padecer síntomas compatibles con la covid para hacerse la prueba PCR, realizar un aislamiento en condiciones adecuadas o tomar una baja laboral, en caso de que tengan derecho a ello. Fue el caso de una trabajadora que llamó al centro de salud explicando que estaba cuidando en régimen de interna a una persona mayor enferma de covid y que ella había empezado también con síntomas. Tenía fiebre y diarrea. Desde el centro se le aconsejó que se realizara la prueba y se sometiera a una revisión médica. Ella insistía que iba a "esperar unos días" a ver como evolucionaba. A los pocos días tuvo que ser ingresada en una unidad de cuidados intensivos con una neumonía bilateral. Tras el alta hospitalaria, y aun con síntomas evidentes de afectación respiratoria, su mayor preocupación era reincorporarse cuanto antes al trabajo, ya que temía por la posible pérdida del mismo. O el caso de otra trabajadora que cuidaba un hombre mayor que se enfermó de covid, y quería saber qué riesgo real tenía de contagiarse, dado que dormía en la misma habitación que él, sin protección. No quería abandonar el lugar de trabajo porque estaba contratada a través de una empresa, pero no tenía reemplazo.

Pese a estar amparadas en la Seguridad Social, se observa como ambas trabajadoras tienen una fuerte percepción de riesgo inminente de pérdida de su trabajo si tramitan su baja laboral. Este abuso de poder que ahora se expresa en algo tan preciado como la vida, ese estar entre la vida y la muerte que representa la posibilidad de enfermar, deja patente la deshumanización con la que son tratadas estas trabajadoras - "Lo que yo, como ser humano pueda vivir o pueda sentir, eso es problema mío", nos decía Fernanda-, esa condición servil desde la que se reproduce este trabajo, que deja en manos de arreglos privados y la ética de la persona empleadora la garantía de los derechos de las trabajadoras. 
Las discriminaciones se agravan en este sector en el que no se contempla la intermediación para garantizar el cumplimiento del contrato o acuerdos pactados entre trabajadora y empleador/a, llegando en algunas situaciones a ejercer este último la potestad absoluta sobre la trabajadora. Las trabajadoras nos han mostrado documentos redactados por sus empleadores/as para que firmen su baja voluntaria para encubrir un despido improcedente. En otros casos, la parte empleadora ha obstaculizado la tramitación del subsidio extraordinario, aun reuniendo las condiciones para solicitarlo. El contrato laboral aparece aquí como ficción que ignora el abuso de poder ejercido por parte de quién emplea (Bofill-Poch y Márquez, 2021).

La necesidad de medidas de protección, seguridad e higiene en el trabajo que ha traído la pandemia ha desvelado una vez más los vacíos del Régimen regulador del empleo de hogar. Las trabajadoras se han tenido que "buscar la vida", comprando los equipos de protección con sus ya míseros salarios, como nos expresa Fernanda que trabaja en régimen de interna cuidando a una mujer de 93 años.

Ellos no me dan el material, pero igual exigen que me proteja. Yo me compro mis mascarillas, mis guantes y mi gel, porque yo sé que si yo no cuido mi salud ellos no van a cuidar de ella. Tengo que protegerme, por ella [la señora] y también por mí, porque yo tengo mi vida y tengo mis familiares y no quiero que a mí me pase nada.

A las trabajadoras se les pide que extremen las precauciones cuando salgan a la calle, que no tomen el transporte público y que "se cuiden". El miedo a que puedan traer el virus de la calle no solo ha restringido sus desplazamientos, sino que en algunos casos las ha expuesto a medidas de higienización deshumanizantes, como nos narraba Eloisa, quien cuida una mujer de 83 años.

La hija hasta me trajo una pantalla para ponerme en la cara, y sí, parecía un robot. La pantalla en la cara, el tapabocas, los guantes, los productos de limpieza, hacía mucho calor. Yo sentía que me ahogaba. De pronto me lo bajaba un poquito en la nariz, y ahí mismo me estaban encima, 'que quiero que subas'. Eran normas de seguridad. Yo hablaba y tenía que gritar y no me entendía la señora. Sudaba mucho, me dio un sarpullido en la boca por esto de tener tapada siempre la boca. Antes de entrar en casa, nos rociaban con desinfectante. Eso sí fue denigrante. Era como los 
campos de concentración, que tenías casi que bañarte afuera, entrábamos lavadas, descalzas. Nos echaban tanta cosa que la ropa se mojaba. Hasta las rueditas del carro, todo.

En este relato se expresa la desafección, descorporización, como si de máquinas se tratasen ("parecía un robot") y la deshumanización en el trato ("nos rociaban con desinfectante... era como los campos de concentración"), añadido a la vigilancia y control constantes ("quiero que subas [la mascarilla]") y desautorización a la que ya nos hemos referido en apartados anteriores.

Esta cosificación, deshumanización y desautorización contrasta con los relatos de las entrevistadas Patricia y Luana, quiénes, precisamente por el miedo a perder el trabajo y por su ética profesional, no han hecho sino exacerbar las medidas de protección.

Yo no salía, para nada. Tenía miedo, no tanto por mí, sino por la yaya. Yo tomé la decisión, por responsabilidad, por cuidarla. Cuando salía intentaba que nadie se me acercase e ir rapidito. Cuando regresaba me limpiaba las manos y la ropa con legía. Como sabía que era una persona vulnerable, yo llegaba, me cambiaba el calzado y trataba de estar con mascarilla cuando conversábamos. Me lavaba las manos, tenía mi botellita de lejía siempre para los zapatos, para mí misma. En la calle, para no llevarle el virus, yo trataba de hacer el mínimo contacto con las personas. Nunca me hice ninguna prueba ni nada, pero yo sabía que el día que yo regresaba a trabajar estaba bien, porque yo me habia cuidado. Y eso fue. Yo habiéndome cuidado tanto, imaginese, y me vengo a contagiar alli en la casa.

Las estrategias desplegadas por las trabajadoras expresan un fuerte sentido de responsabilidad. Desde Sindillar/Sindihogar nos hablan del "auto-confinamiento grupal", para referirse al modo en que las propias trabajadoras limitaron de forma voluntaria su círculo de relación social. El miedo a ser agente de contagio expresa aquí el miedo a contagiar a una persona mayor que se percibe como frágil, con la que además se establecen lazos afectivos, cuya vida, dicen ellas, está en sus manos. Las trabajadoras sienten responsabilidad sobre la persona que cuidan, más cuando la familia delega en ellas su cuidado principal. Así lo señalaba Fernanda, cuidadora interna de una mujer de 93 años: "Los primeros meses de pandemia, ellos dejaron prácticamente toda la responsabilidad en mis manos”. 
Aparece aquí también la carga y fuerte ambivalencia afectiva que impregna la relación laboral del hogar.

La situación de incertidumbre ante la posible pérdida del empleo, más acuciante para quienes están en situación administrativa irregular, ha colocado a estas trabajadoras en una situación de gran vulnerabilidad, forzándolas a "aceptarlo todo", como nos expresa Patricia, ya no solo en términos de derechos laborales, también en términos de desatención de sus propias familias al tener que confinarse.

Antes trabajaba de noche, de 18 a 9h de la mañana. Durante el día la dejaba en un centro de día y yo quedaba libre. Apenas empezó el confinamiento me confiné, porque cuidada una persona mayor, y tuve que quedarme con ella, para cuidarla, porque no podía salir ni entrar. Dejé a mi hijo de 14 años con su papá, en un piso viviendo, y ahí empezaron los problemas. El papá comenzó a tomar, los dueños del piso trajeron más gente a vivir, dormían en la sala, era un caos en la casa. Llegué a llamar a la policía. Yo hablaba por teléfono con mi hijo. No podía salir. Viví un momento muy agobiante en ese tiempo. Yo estaba confinada cuidando la yaya. O decidía quedarme, o decidía perder el trabajo. Como no tengo papeles, para mí era muy difícil no aceptar. He aceptado todo.

\section{REFLEXIONES FINALES}

Los interrogantes que motivaron la escritura de este texto tomaban relación con los efectos que podría estar teniendo el miedo al contagio en las condiciones laborales en las mujeres de origen inmigrante empleadas de hogar y de cuidados. Sin duda, el sector más precarizado de la economía de los cuidados, regulado por un "Régimen especial" sostenido en relaciones más cercanas a la servidumbre que a las laborales. Sector, que ha crecido en nuestro contexto a la par que la emigración procedente del Sur global desde la década de los 90 del siglo pasado. Quizás nuestro propio miedo, inoculado desde que se decretó la pandemia por la OMS y empezamos a procesar las insoportables cifras de muertes y de contagios, nos confrontó con otro miedo más tangible y cotidiano al escuchar a las trabajadoras de hogar: su miedo a la pérdida de su empleo y con ello, a su propio sostén y el de las personas que dependen de ellas, tanto en sus países de origen como en el país 
de residencia. El cuidado de las personas a las que cuidaban y su autocuidado hubo de ser extremado, les iba la vida en ello, pero no solo por la amenaza del virus, sino porque estaba en juego su supervivencia diaria: su salario, aun estando muy lejos de responder a la sobrecarga de trabajo física y emocional en un momento como el que estamos viviendo. El miedo de sus empleadores, sin embargo, sí ha tenido unos efectos devastadores sobre ellas, sobre su ya precaria economía. Muchas han perdido sus trabajos, como han dado cuenta diferentes organizaciones sociales. Pero las que los han mantenido, o encontraron empleo en este sector en medio de la pandemia, han sentido, además de la sobrecarga de trabajo, lo poco que importan a las familias para las que trabajan. Lo poco que se valora su trabajo, salvo para ser esos "robots" deshumanizados siempre disponibles que cuidan a nuestros familiares. Las diferentes percepciones del miedo al contagio que expresan las posiciones sociales asimétricas desde las que actúan personas cuidadas, familias empleadoras y trabajadoras, más que cálculos racionales y objetivos, nos habla de ordenamientos morales no siempre presididos por la justicia social (Douglas, 1996). El miedo, como el riesgo, emerge como categoría construida en la interacción social, cuya significación debemos buscarla en un marco regulatorio laboral y de extranjería que despoja a las trabajadoras de sus derechos, pero también en una economía de los cuidados y unas políticas institucionales que, en contexto de pandemia, han desatendido e invisibilizado los abusos y padecimientos que produce nuestro sistema de cuidados. Ello remite, en última instancia, a esta posición liminar del sector, la cual subyace a su falta de reconocimiento como trabajo. Sin duda, tenemos una gran deuda social hacia estas mujeres que siguen estando en primera fila, trabajando en ese escenario tan impenetrable del hogar salvo para las relaciones de mercado en su cara más extractiva y abusiva.

\section{AGRADECIMIENTOS}

Este artículo presenta parte de los resultados del proyecto CUMADE "El cuidado importa. Impacto de género en las cuidadoras/ es de mayores y dependientes en tiempos de la COVID-19", dirigido por Dolors Comas d'Argemir de la Universitat Rovira i Virgili y finan- 


\section{ciado por el FONDO SUPERA COVID-19 Santander-CSIC-CRUE.}

Agradecemos a su directora y a todo el equipo de investigación, especialmente de la unidad de trabajo sobre empleo del hogar, sus reflexiones y aportaciones. Agradecemos también a todas las personas y entidades participantes entrevistadas para el estudio, cuyos testimonios y reflexiones son parte esencial de nuestra aportación.

\section{REFERENCIAS BIBLIOGRÁFICAS}

Álvarez, A. (2007). Habitando espacios de frontera: Más allá de la victimización y la idealización de las mujeres migrantes. En E. Imaz (Ed.), La materialidad de la identidad (pp. 199-218). Donostia: Hariadna Editorial.

Anderson, B. (2000). Doing the dirty work? The global politics of domestic labour. London: Zed Books.

Arruzza, C., Bhattacharya, T. y Fraser, N. (2019). Manifiesto de un Feminismo para el $99 \%$. Barcelona: Herder.

Benería, L. (2008). The crisis of care, international migration, and public policy. Feminist Economics, 14(3), 1-21.

Bofill-Poch, S. y Márquez, R. (2021). Perjuicios de un trabajo especial: la falta de acceso a la justicia en el empleo de hogar y cuidados en España. En D. Comas d'Argemir y S. Bofill-Poch (Eds.), El cuidado de mayores y dependientes: avanzando hacia la igualdad de género y la justicia social. Barcelona: Icaria.

Bofill-Poch, S. y Márquez, R. (2020). Indefensión, injusticia y merecimiento en el colectivo de trabajadoras del hogar: análisis de casos judicializados. Etnográfica. Revista do Centro em Rede de Investigação em Antropologia, 24(1), 225-244. https://doi.org/10.4000/etnografica.8487

Bofill-Poch, S. (2017). Otro trabajo del hogar es posible": procesos de lucha por el reconocimiento y dignificación de los cuidados en tiempos de crisis. Quaderns-e de l'Institut Català d'Antropologia, 22(2), 133-149. https://www.antropologia.cat/files/9_Bofill.pdf

Briones, E., Agudelo, A., López, M. J., Vives, C., Ballester, F. y Ronda, E. (2014). Percepción de las mujeres inmigrantes del servicio doméstico sobre los efectos de la regulación del sector en España. Gaceta Sanitaria, 28(2): 109-115.

Carrasco, C. (2003). El cuidado: ¿coste o prioridad social? Ponencia presentada en el Congreso Internacional Cuidar cuesta: costes y beneficios del cuidado. Donostia, 13 y 14 de octubre de 2003.

Carrasco, C. (1991). El trabajo doméstico y la reproducción social. Madrid: Instituto de la Mujer.

Comas d'Argemir, D. (2014). Los cuidados y sus máscaras: retos para una antropología feminista. Mora, 20, 167-182. 
Comas d'Argemir, D. (2000). Mujeres, Familia y Estado de Bienestar. En T. Del Valle (Ed.), Perspectivas feministas desde la antropología social (pp. 187-204). Barcelona: Ariel Antropología.

Comas d'Argemir, D. (1995). Trabajo, género y cultura. La construcción de desigualdades entre hombres y mujeres. Barcelona: Icaria.

Del Pino, E., Moreno-Fuentes, F. J., Cruz-Martínez, G., Hernández-Moreno, J., Moreno, L., Pereira-Puga, M., y Perna, R. (2020). Informe Gestión Institucional y Organizativa de las Residencias de Personas Mayores y COVID-19: dificultades y aprendizajes. Madrid: Instituto de Políticas y Bienes Públicos (IPP-CSIC). Recuperado de http://dx.doi.org/10.20350/ digitalCSIC/12636

Del Valle, T. (2003). Contenidos y significados de nuevas formas de cuidado. Ponencia presentada en el Congreso Internacional Cuidar cuesta: costes y beneficios del cuidado, Donostia, 13 y 14 de octubre.

Díaz-Gorfinkiel, M. y Martínez-Buján, R. (2018). Mujeres migrantes y trabajos de cuidados: transformaciones del sector doméstico en España. Panorama Social, 27, 105-118.

Douglas, M. (1996 [1985]). La aceptabilidad del riesgo según las ciencias sociales. Barcelona: Paidós.

Durán, M ${ }^{\mathrm{a}}$ A. (2002). Los costes invisibles de la enfermedad. Bilbao: Fundación BBVA.

Esteban, M. L. (2019). El feminismo y las transformaciones en la política. Barcelona: Bellaterra.

Federici, S. (2013). Revolución en punto cero. Trabajo doméstico, reproducción y luchas feministas. Madrid: Traficantes de sueños.

Gorban, D. (2012). Empleadas y empleadoras, tensiones de una relación atravesada por la ambigüedad. Revista Española de Investigaciones Sociológicas (REIS), 140 (1), 29-48.

Gregorio Gil, C. (2021). Hogares, cuidados y migraciones en tiempos de pandemia desde una mirada feminista y decolonial. Hariak (en prensa)

Gregorio Gil, C. (2017). ¿Por qué hablar de cuidados cuando hablamos de migraciones transnacionales? Quaderns-e de l'Institut Català d'Antropologia, 22(2), 49-64. https://www.raco.cat/index.php/Quadern seICA/article/view/333113

Gregorio Gil, C. (2009). Políticas de conciliación, externalización del trabajo doméstico y de cuidados y migraciones transnacionales. En III Congreso de Economía Feminista. La economía feminista en un contexto de crisis global. Baeza, 2-3 abril. Recuperado de http:/www.upo.es/ congresos/export/sites/congresos/economiafeminista/documentos/ Carmen_Gregorio_gil.pdf

Gregorio Gil, C. (2007). "Trabajando honestamente en casa de familia": entre la domesticidad y la hipersexualización. Estudos Feministas 15(3), 699-716. https://periodicos.ufsc.br/index.php/ref/article/view/S0104026X2007000300013/1480 
Gregorio Gil, C. (2004). Entre la inclusión y la exclusión de la ciudadanía: procreadoras, madres y personas. Asparkía. Investigació Feminista, 15, 11-25. Recuperado de https://www.e-revistes.uji.es/index.php/asparkia/ article/view/618

Gregorio Gil, C. (1998). Migración femenina: Su impacto en las relaciones de género. Madrid: Narcea.

Gregorio Gil, C., Alcázar Campos, A. y Huete Navarro, M. (2003). ¿'Muchacha', 'chacha', 'una más de la familia'?: mujeres inmigrantes en el servicio doméstico en la ciudad de Granada. En III Seminario sobre la investigación de la inmigración extranjera en Andalucía (215-228). Sevilla: Dirección General de Coordinación de Políticas Migratorias.

Herrero, Y. (2019). Poner la vida en el centro. Nuestra bandera. Revista de debate político, 244, 17-22.

ILO (2013). Domestic Workers Across the World: Global and Regional Statistics At The Extent Of Legal Protection. Recuperado de http://www. ilo.org/wcmsp5/groups/public/---dgreports/---dcomm/---publ/documents/ publication/wcms_173363.pdf

Ley 27/2011, de 1 de agosto sobre actualización, adecuación y modernización del sistema de Seguridad Social (BOE n ${ }^{\circ}$ 184). https:/www.boe.es/ buscar/doc.php?id=BOE-A-2011-13242

Ley 39/2006, de 14 de diciembre, de Promoción de la Autonomía Personal y Atención a las personas en situación de dependencia (BOE n 299) https:/www.boe.es/eli/es/l/2006/12/14/39/con

Mahía, R. (2021). Los efectos del COVID-19 sobre la inmigración en España: economía, trabajo y condiciones de vida. Anuario CIDOB de la Inmigración 2020 (enero de 2021), 68-81.

Maquieira, V., Gregorio, C. y Gutiérrez, E. (2000). Políticas públicas, género e inmigración. En P. Pérez Cantó (Coord.), También somos ciudadanas (371-442). Madrid: Ediciones de la UAM.

Márquez, R. y Bofill-Poch, S. (2020). De redistribución y reconocimiento: acusaciones penales, vulneración de derechos y reclamos de justicia en el trabajo del hogar y los cuidados. En M. Aramburu y S. Bofill (Eds.), Crisis y sentidos de injusticia: tensiones conceptuales y aproximaciones etnográficas. Barcelona: Edicions Universitat de Barcelona.

Martínez-Buján, R. (2011). La reorganización de los cuidados familiares en un contexto de migración internacional, Cuadernos de Relaciones Laborales, 22(4), 406-418.

Mestre, R. (2005). Feminisme, dret i immigració: una crítica feminista al dret d'estrangeria. Tesis doctoral. Universitat de València.

Monteros, S. (2017). La emergencia de lo político en el cruce entre migraciones femeninas, apoyo mutuo y participación política: la experiencia de la Red de Mujeres Latinoamericanas y del Caribe en España. Quaderns-e de l'Institut Català d'Antropologia, 22(2), 150-166.

Moré, P. (2020). Cuidados y crisis del coronavirus: el trabajo invisible que sostiene la vida. Revista Española de Sociología (REIS) 29(3), 737-745. 
Offenhenden, M. (2017). 'Si hay que romperse una, se rompe'. El trabajo del hogar y la reproducción social estratificada. Tesis doctoral. Universitat Rovira i Virgili.

Otxoa, I. (2020). El subsidio que no llega: una promesa incumplida. El Salto (24 de julio). Recuperado de https://www.elsaltodiario.com/opinion/ subsidio-trabajadoras-hogar-no-llega-promesa-incumplida-devaluacioncondiciones

Parella, S. (2021). El sector del trabajo del hogar y de cuidados en España en tiempos de COVID-19. Anuario CIDOB de la Inmigración 2020 (enero de 2021), 102-114.

Pérez-Orozco, A. (2006). Amenaza tormenta: la crisis de los cuidados y la reorganización del sistema económico. Revista de economía crítica, 5, 7-37.

Real Decreto-ley 11/2020, de 31 de marzo, por el que se adoptan medidas urgentes complementarias en el ámbito social y económico para hacer frente al COVID-19 (BOE-A-2020-4208) https://www.boe.es/buscar/doc. php?id=BOE-A-2020-4208

Real Decreto-ley 8/2020, de 17 de marzo, de medidas urgentes extraordinarias para hacer frente al impacto económico y social del COVID-19 (BOEA-2020-3824) https://www.boe.es/buscar/act.php?id=BOE-A-2020-3824

Real Decreto 1620/2011, de 14 de noviembre, por el que se regula la relación laboral de carácter especial del servicio del hogar familiar (BOE $\left.\mathrm{n}^{\circ} 277\right)$. https://www.boe.es/buscar/doc.php?id=BOE-A-2011-17975

Real Decreto-Ley 29/2012, de 28 de diciembre, de mejora de gestión y protección social en el Sistema Especial para Empleados de Hogar (BOE $\mathrm{n}^{\circ}$ 314). https:/www.boe.es/diario_boe/txt.php?id=BOE-A-2012-15764 